\title{
DIREITO FUNDAMENTAL À TUTELA JURISDICIONAL EFETIVA E LIMITES EM TERMOS DE COMPETÊNCIA DE INSTITUIÇÕES DO SISTEMA DE JUSTIÇA CIVIL ${ }^{1}$
}

\section{FUNDAMENTAL RIGHT TO AN EFFECTIVE JURISDICTIONAL PROTECTION AND CIVIL JUSTICE SYSTEM INSTITUTIONS JURISDICTION LIMITS}

Luis Alberto Reichelt Mestre e Doutor em Direito pela UFRGS. Professor nos cursos de graduação, especialização, mestrado e doutorado em Direito da PUCRS. Procurador da Fazenda Nacional em Porto Alegre (RS). Porto Alegre/RS. E-mail: luis.reichelt@ pucrs.br

Camila Victorazzi Martta Doutoranda e Mestre em Direito pela PUCRS. Professora de Processo Civil em Cursos de Especialização. Advogada. Porto Alegre/RS. E-mail: camila.martta@edu.pucrs.br

\section{Alan Jece Baltazar}

Doutorando em Direito na PUCRS. Mestre em Direito pela Escola Paulista de Direito - EPD. Bacharel em Direito pela PUCRS. Tabelião de notas e registrador civil em Lagoão, Comarca de Sobradinho (RS). Lagoão/RS. E-mail: alanjece@gmail.com

RESUMO: O presente artigo faz uma tripla abordagem acerca do direito fundamental à tutela jurisdicional efetiva. Inicialmente, a partir do ponto de vista do direito fundamental ao juiz natural, é analisada a relevância da questão objeto do recurso especial, considerando a recente aprovação da proposta de Emenda à Constituição 10/2017. Em seguida, considerase os limites impostos pela Súmula $\mathrm{n}^{\circ} 7$ do Superior Tribunal de Justiça como fator de

\footnotetext{
${ }^{1}$ Artigo recebido em 26/11/2021 e aprovado em 03/12/2021.
} 
delimitação do âmbito de competência do referido tribunal. Ao final, reflete-se sobre a ampliação do acesso à justiça a partir dos movimentos de desjudicialização e de extrajudicialização no contraste com a limitação legal das atribuições da atividade notarial.

PALAVRAS-CHAVE: Justiça Civil; direito fundamental à tutela jurisdicional efetiva; limitações da competência; Poder Judiciário; atividade notarial.

\begin{abstract}
This article takes the fundamental right to effetctive judicial protection under three different perspectives. Initially, from the point of view of the fundamental right to a natural judge, it analyses the relevance of the issue object of the recurso especial, considering the recent approval of the Constitutional Amendment proposal n. 10/2017. Then, it considers the Súmula n. 7 of the Superior Tribunal de Justiça as a jurisdiction range stablishment factor of the so mentioned court. Finally, it takes into account the expansion of access to justice from the dejudicialization and extrajudicialization movements considering the existence of legal limitations of the attributions of the notarial activity.
\end{abstract}

KEYWORDS: Civil Justice; fundamental right to effective jurisdictional protection; jurisdictional limits; judicial power; notarial activity.

\title{
1. INTRODUÇÃO
}

A oferta de tutela jurisdicional efetiva em favor das partes, compromisso erguido como uma das exigências decorrentes da leitura crítica do art. $5^{\circ}, \mathrm{XXXV}$ da Constituição Federal, assume a feição de direito fundamental e, sob essa ótica, sujeita-se a toda a crítica que é usual diante do emprego de direitos fundamentais. A aplicabilidade imediata inerente a tais direitos, ao mesmo tempo em que se revela em um trunfo diante da inércia daqueles de quem se espera por providências com vistas à regulamentação do modo de ser das fórmulas constitucionalmente desenhadas, acaba por dialogar com uma premissa inarredável no contexto do direito à tutela jurisdicional efetiva, qual seja o dos limites a serem respeitados do ponto de vista da competência jurisdicional associada aos entes responsáveis pelas prestações que veiculam a proteção a ser alcançada ao jurisdicionado. $\mathrm{O}$ atendimento a essa exigência acaba servindo como condição de validade dos atos praticados por órgãos 
jurisdicionais e, por consequencia, atuam como limites à implementação da tutela efetiva em favor do jurisdicionado, em uma equação difícil

$\mathrm{O}$ respeito a balizas ligadas à competência também acaba por ser um fator a ser ponderado na oferta de tutela jurisdicional efetiva, de outro lado, em se cotejando a atuação do Poder Judiciário no contraste com a de outros atores que com ele trabalham exercendo tarefas análogas com vistas à oferta de acesso à justiça. Nesse sentido, a existência de condicionamentos distintos a serem observados por diferentes atores do sistema de justiça, resultado da comparação entre as diversas vias que levam a um mesmo resultado, também é um desafio em se considerando que o compromisso associado aos órgãos do Poder Judiciário com vistas à oferta de tutela jurisdicional efetiva acaba sendo necessariamente trazido à tona toda vez que se coloca o agir dos magistrados no contraste com outras alternativas projetadas no âmbito extrajudicial destinadas à produção dos mesmos efeitos jurídicos em favor do cidadão.

O presente trabalho propõe-se, pois, a examinar essas problemáticas lançando luzes sobre três questões que servem como palco para o desenvolvimento de ideias importantes em torno das relações entre o direito fundamental à tutela jurisdicional efetiva e os limites inerentes às instituições envolvidas no sistema projetado com vistas à oferta de acesso à justiça no âmbito cível, em um exame que revela não só as diferentes conformações assumidas por esse direito fundamental, mas também a forma como ele interage com outras exigências presentes no sistema. Nesse sentido, analisar-se-á, inicialmente, as relações entre o direito fundamental à tutela jurisdicional efetiva, o direito fundamental ao juiz natural e a relevância da questão objeto de recursos especiais, objeto da Proposta de Emenda à Constituição $n^{\circ}$ 10/2017, recentemente aprovada pelo Senado Federal. Em um segundo momento, propor-se-á uma reflexão a respeito da conformação do direito fundamental à tutela jurisdicional efetiva no contraste com os limites à atuação dos tribunais superiores por força de regras de competência jurisdicional, em um exame que lançará luzes sobre a correta exegese a ser ofertada na aplicação da Súmula n 7 do Superior Tribunal de Justiça. Por fim, tratar-se-á do direito fundamental à tutela jurisdicional efetiva de modo a cotejar os limites a serem observados na atuação da atividade notarial, pensada como agir capaz de ofertar resultados jurídicos equivalentes a cidadãos em termos de acesso à justiça mediante o recurso 
à desjudicialização e à extrajudicialização de atividades prestacionais também desenvolvidas por órgãos do Poder Judiciário.

\section{DAS RELAÇÕES ENTRE O DIREITO FUNDAMENTAL À TUTELA} JURISDICIONAL EFETIVA, O DIREITO FUNDAMENTAL AO JUIZ NATURAL E A RELEVÂNCIA DA QUESTÃO OBJETO DE RECURSOS ESPECIAIS

O direito fundamental ao juiz natural, inscrito no art. $5^{\circ}$, XXXVII e LIII da Constituição Federal, estabelece uma exigência de previsibilidade e de segurança em favor do jurisdicionado, dispondo no sentido de que a prolação de decisões judiciais que possam exercer influência sobre a sua esfera jurídica somente deve ser considerada válida na medida em que tais comandos tenham sido proferidos pela autoridade à qual o ordenamento jurídico tenha previamente atribuído poder para assim proceder. Essa leitura, condizente com o previsto quando de sua concepção original em 1215 na Magna Charta inglesa, mostra que a predeterminação das regras quanto à competência para a prática de atos processuais funciona como ferramenta fundamental para que se impeça que o exercício do poder de julgar acabe sendo refém de excepcionais manifestações de vontade dominantes em um determinado momento histórico ${ }^{2}$.

A essa dimensão tradicional do direito fundamental ao juiz natural soma-se, de maneira mais recente, um outro igualmente importante, qual seja o relativo à realização de escolhas eficientes ${ }^{3}$ pelo legislador com vistas à determinação da competência jurisdicional ${ }^{4}$. Em um mundo em constante transformação, no qual cada vez mais a realidade mais exige das instituições, levando-as aos limites da sua capacidade de atender às demandas que lhe são trazidas, uma das alternativas que se apresenta é justamente o redesenho das regras de competência jurisdicional de modo a fazer com que as construções culturais projetadas no plano do Direito sejam capazes de ofertar o melhor resultado possível diante das condições existentes.

\footnotetext{
${ }^{2}$ Sobre o ponto, ver SILVA, Carlos Augusto. O princípio do juiz natural. Revista da Ajuris, vol. 30, p. 9-28, mar. 2003.

${ }^{3}$ Para um panorama a respeito das múltiplas acepções da noção de eficiência e de suas potenciais aplicações no âmbito do Direito Processual Civil, ver, por todos, JOBIM, Marco Félix. As Funções da Eficiência no Processo Civil Brasileiro. São Paulo: Revista dos Tribunais, 2017.

${ }^{4}$ Uma leitura importante a respeito do tema é o trabalho de CABRAL, Antonio do Passo. Juiz Natural e Eficiência Processual. São Paulo: Revista dos Tribunais, 2021.
} 
Um exemplo emblemático a esse respeito pode ser visto na Proposta de Emenda à Constituição no 10/2017, aprovada no Senado Federal em 03.11.2021 . De acordo com a novidade constitucional em questão, no recurso especial, o recorrente deve demonstrar a relevância das questões de direito federal infraconstitucional discutidas no caso, nos termos da lei, a fim de que o Tribunal examine a admissão do recurso, somente podendo não o conhecer por esse motivo pela manifestação de dois terços dos membros do órgão competente para o julgamento. Notável, no ponto, a simetria o citado comando e aquele já preexistente no parágrafo terceiro do art. 102 da Constituição Federal, que dispõe sobre a repercussão geral do recurso extraordinário ${ }^{6}$.

O parágrafo segundo acrescido ao art. 105 da Constituição Federal prevê uma pauta mínima de casos nos quais se considera que haverá a referida relevância, aí incluindo questões que envolvem juízo de qualidade quanto à matéria envolvida (ações penais, ações de improbidade administrativa e ações que possam gerar inelegibilidade), quanto ao valor da causa (ações cujo valor de causa ultrapasse quinhentos salários mínimos) e quanto à preocupação em assegurar integridade, coerência e estabilidade da jurisprudência do Superior Tribunal de Justiça (hipóteses nas quais o acórdão recorrido contrarie jurisprudência dominante do citado tribunal). Redesenha-se a admissibilidade do recurso previsto no art. 105, III do texto constitucional de modo que, em verdade, redimensiona-se o papel do próprio Superior Tribunal a partir da exigência de atendimento ao novel requisito de admissibilidade recursal. Deixa o Superior Tribunal de Justiça de ser um tribunal ao qual

\footnotetext{
${ }^{5}$ BRASIL. Senado Federal. Proposta de Emenda à Constituição n ${ }^{\circ}$ 10, de 2017. Acrescenta $\S 1^{\circ}$ ao art. 105 da Constituição Federal e renumera o atual parágrafo único. Disponível em https://www25.senado.leg.br/web/atividade/materias/-/materia/128403. Acesso em 19.11.2021.

${ }^{6}$ A respeito da exegese do citado comando constitucional, ver, exemplificativamente, MEDINA, José Miguel Garcia. Prequestionamento, repercussão geral da questão constitucional, relevância da questão federal: admissibilidade, processamento e julgamento dos recursos extraordinário e especial. 7. ed. São Paulo: Rev. dos Tribunais, 2017; SOUZA, Artur César de. Recurso extraordinário e recurso especial: pressupostos e requisitos de admissibilidade no novo CPC: de acordo com a Lei 13.256, de 4/2/2016. São Paulo: Almedina, 2017; PINTO, José Guilherme Berman Corrêa. Repercussão geral no recurso extraordinário. 2. ed. Curitiba: Juruá, 2016; SILVEIRA, José Néri da. Reflexos da exigência de 'repercussão geral das questões constitucionais discutidas no caso' sobre a natureza e a amplitude do recurso extraordinário. Revista do Tribunal Regional Federal da Quarta Região, vol. 88, p. 15-44, 2015; CÔRTES, Osmar Mendes Paixão. Recurso extraordinário: da Constituição Federal de 1988 ao atual CPC. Revista de Processo, vol. 289, p.21-45, mar. 2019; RIBEIRO, Flávia Pereira. Conceito e análise da repercussão geral. Revista Síntese de Direito Civil e Processual Civil, vol. 110, p. 84-86, nov./dez. 2017; SILVA, Christine Oliveira Peter da. Repercussão geral em evolução: narrativa histórica, teórica e metodológica. Revista Síntese de Direito Civil e Processual Civil, vol. 110, p. 9-32, nov./dez. 2017; OLIVEIRA, Pedro Miranda de. Para uma efetividade maior do instituto da repercussão geral das questões constitucionais. Revista Dialética de Direito Processual vol.145, p. 60-81, abr. 2015.
} 
podem ser levadas todas as questões listadas no citado art. 105, III da Constituição Federal e passa a enfrentar as citadas questões apenas nos casos em que presente a relevância nos termos do previsto no âmbito constitucional ou, ainda, em outras hipóteses porventura previstas em lei.

Sobre esse último aspecto, cumpre destacar que a referida emenda constitucional acaba por permitir, por via transversa, que o legislador infraconstitucional seja o detentor da última palavra sobre a extensão dessa nova configuração do tribunal na medida em que estabeleça uma maior ou menor amplitude dos casos nos quais se faça reconhecida a presença da relevância da questão. Também aqui há uma certa simetria em relação à forma como projetada a regulamentação do regime jurídico aplicável em relação à repercussão geral de recursos extraordinários, também confiada ao legislador infraconstitucional.

Aprofundando o raciocínio acima apresentado, observa-se, ainda, que, tomando em conta a literalidade do texto da alteração constitucional conforme aprovado pelo Senado Federal, é de se considerar como uma alternativa a opção do legislador por trabalhar com linguagem aberta ao dispor sobre a aferição da relevância para fins de admissibilidade de recursos especiais. Tal abordagem importaria, na prática, por deixar a definição quanto à casuística em relação a um requisito de admissibilidade recursal nas mãos dos próprios magistrados responsáveis pela realização do referido exame. Para além de reflexos sistêmicos decorrentes de um maior ou menor número de recursos que venham a ser admitidos ou inadmitidos, nessa hipótese reside um considerável risco do ponto de vista da segurança jurídica, qual seja o de que magistrados atuantes no tribunal em que proferida a decisão que se busca reformar na via do recurso especial viessem a delimitar, por via transversa, a competência do Superior Tribunal de Justiça. Outra hipótese, não menos problemática, é a de que o próprio Superior Tribunal de Justiça acabasse, ao proferir decisões sobre a caracterização ou não de relevância das questões para fins de admissibilidade de recursos especiais, assumindo a responsabilidade pela definição do seu âmbito de competência.

Em ambos os casos, tem-se que tais abordagens não deixam de respeitar a literalidade do constante do art. 5\%, XXXVII e LIII da Constituição Federal, por certo que abriria as portas para todo um debate a respeito da obediência ao espírito constante em tais regras, que reclama a predeterminação das regras de competência jurisdicional, projeção da exigência 
de segurança jurídica ${ }^{7}$ que se apresenta como condição para que se cogite de prolação de decisões judiciais que possam impor qualquer restrição à esfera jurídica das partes. $\mathrm{Na}$ hipótese em que se admitisse que a definição da relevância pudesse ser feita diretamente pelo magistrado, sem que houvesse a mediação da lei entre a voz do juiz e a linguagem constitucional, tem-se que a preservação da segurança jurídica certamente passaria pelo compromisso dos magistrados responsáveis pelo juízo de admissibilidade recursal com vistas à preservação da coerência, integridade e estabilidade da jurisprudência formada em torno dos critérios a serem observados, de modo que a lacuna deixada em função da ausência de padrões legalmente dispostos acabaria sendo suprida pela confiança dos jurisdicionados na experiência consolidada dos tribunais, expressa em orientações consolidadas em julgamentos anteriores.

\section{DIREITO FUNDAMENTAL À TUTELA JURISDICIONAL EFETIVA E OS LIMITES À ATUAÇÃO DOS TRIBUNAIS SUPERIORES POR FORÇA DE REGRAS DE COMPETÊNCIA JURISDICIONAL: O CASO DO SUPERIOR TRIBUNAL DE JUSTIÇA E A SÚMULA No 7}

Um dos temais mais tormentosos que se tem para reflexão no que se refere às relações entre competência jurisdicional e a oferta de tutela jurisdicional efetiva é o que envolve a posição do Superior Tribunal de Justiça diante de casos nos quais vem a ser chamado a reexaminar decisões que versem sobre matéria probatória em sede de recurso especial.

Em uma primeira aproximação, o que se vê é a presença de uma situação que poderia ser vista como um sinal de crise do ponto de vista do desrespeito ao direito à tutela jurisdicional efetiva. Amparado na orientação expressa na Súmula $n^{\circ} 7$, segundo a qual " $a$ pretensão de simples reexame de prova não enseja recurso especial", o Tribunal da Cidadania acaba por proferir decisão monocrática terminativa em face de recurso, frustrando a expectativa da parte sucumbente. Consideradas tais decisões em um cenário no qual há a notícia de que em mais de meio milhão de julgados o referido tribunal não apreciou a questão

\footnotetext{
${ }^{7}$ A amplitude e complexidade inerentes à noção de segurança jurídica podem ser vistas, por todos, na obra de ÁVILA, Humberto. Teoria da Segurança Jurídica. 6a edição. Salvador: Juspodivm, 2021.
} 
de mérito recursal ${ }^{8}$, fica, em um primeiro olhar, a sensação de que haveria, na espécie, uma espécie de obstáculo a ser transposto.

Contudo, a questão é mais complexa do que as aparências possam sugerir. Nesse sentido, uma primeira guia a ser considerada diz respeito à função prevista constitucionalmente do Superior Tribunal de Justiça, contida no artigo 105, III, c da Constituição Federal de 1988, segundo o qual compete ao Superior Tribunal de Justiça julgar, em recurso especial, as causas decididas em única ou última instância, pelos Tribunais Regionais Federais ou pelos tribunais dos Estados, do Distrito Federal e Territórios, quando a decisão recorrida der à lei federal interpretação divergente da que lhe haja atribuído outro tribunal. Da leitura do texto constitucional é possível identificar não apenas que a competência do Superior Tribunal de Justiça é limitada à interpretação da lei federal, como também que sua primordial função é a unificação dessa interpretação, a fim de construir um sistema de padrões decisórios que alcance uma universalidade e que seja capaz de gerar segurança jurídica aos cidadãos.

Em perspectiva histórica, observa-se que o Superior Tribunal de Justiça foi criado pela Constituição Federal de 1988 como uma corte responsável por dar a última palavra a respeito da interpretação da lei infraconstitucional federal ${ }^{9}$, com papel que se desenvolve a partir da consideração de trabalho que até então competia ao Supremo Tribunal Federal. A incompreensão a respeito do significado inerente à função de controle quanto à unidade $\mathrm{e}$ uniformidade do Direito oriundo da interpretação de leis federais trouxe a falsa ideia de que o Superior Tribunal de Justiça deveria atuar como um revisor dos julgamentos proferidos pelos tribunais estaduais, do Distrito Federal e Territórios, ou, ainda, pelos Tribunais Regionais Federais, atuando como uma espécie de terceiro grau de jurisdição, dando ensejo ao surgimento de um crescente volume de recursos nos quais as partes pleiteavam a análise da matéria debatida no primeiro grau e já revista pelas Cortes Estaduais.

\footnotetext{
${ }^{8}$ Segundo o Relatório Estatístico do Superior Tribunal de Justiça, "em 2019, foram proferidas no STJ 503.699 decisões terminativas, considerando as $129.958(25,80 \%)$ decisões proferidas em recursos internos entre Agravos Regimentais (AgRg), Agravos Internos (AgInt) e Embargos de Declaração (EDcl) (...)" (SUPERIOR TRIBUNAL DE JUSTIÇA. Assessoria de Modernização e Gestão Estratégica. Coordenadoria de Gestão da Informaão. $\quad$ Relatório $\quad$ Estatístico $2020 . \quad$ Disponível em https://www.stj.jus.br/webstj/Processo/Boletim/verpagina.asp?vPag=0\&vSeq=357. Acesso em 18.11.2021. p. 16)

${ }^{9}$ MITIDIERO, Daniel. Cortes Superiores e Cortes Supremas: Do Controle à Interpretação, da Jurisprudência ao Precedente. 3.ed. São Paulo: Revista dos Tribunais, 2017. p.93.
} 
Para que se possa dimensionar a competência do Superior Tribunal de Justiça em tal contexto, observe-se que o recurso especial é uma espécie sujeita a um regime jurídico no qual sua hipótese de cabimento é de fundamentação vinculada, de modo que tal insurgência não é admissível senão pelos motivos expressamente descritos na ordem constitucional. Ainda que haja alguma injustiça eventualmente cometida pelos tribunais estaduais e regionais, o julgamento do recurso especial não se confunde com o trabalho desenvolvido em um terceiro grau de jurisdição, na medida em que não se presta para a correção do julgado recorrido, mas, antes, para o contraste entre o que foi decidido e a norma oriunda da interpretação da lei federal ${ }^{10}$, cabendo ao tribunal zelar pela unificação e uniformização do seu sentido ${ }^{11}$. As alegações sobre fato que se constituem em cenário do problema judicializado acabam integrando o debate dos autos sob a forma de matéria sobre a qual não se admite mais o estabelecimento de controvérsia, de modo que sobre elas não mais se fará qualquer conferência sobre se e/ou como ocorreram.

Avançando na mesma trilha ora percorrida, cabe lembrar, com Nelson Nery Júnior, que não é de todo correta a afirmação no sentido de que é vedado o exame de prova no âmbito do recurso especial ${ }^{12}$. Se, de um lado, o Superior Tribunal de Justiça realiza um julgamento de cassação da decisão recorrida nos casos em que há negativa de vigência de norma jurídica extraída da interpretação de lei, é certo, entretanto, que a Corte trabalha como juízo de revisão em um segundo momento, aplicando o direito à espécie, momento no qual é possível a aplicação de normas relativas à valoração da prova. Acertada, no ponto, a visão de Teresa Arruda Alvim e Bruno Dantas, para quem a revalorização das provas tem sido permitida quando é desobedecida norma que determina o valor que a prova pode ter em função do caso concreto ${ }^{13}$.

Outra abordagem igualmente relevante é a que parte da leitura proposta por Daniel Mitidiero, ao anotar que a vedação inerente à Súmula $n^{\circ} 7$ do Superior Tribunal de Justiça

\footnotetext{
${ }^{10}$ NERY JÚNIOR, Nelson. Teoria Geral dos Recursos. 6.ed. São Paulo: Revista dos Tribunais, 2004. p. 441.

11 MITIDIERO, Daniel. Cortes Superiores e Cortes Supremas: Do Controle à Interpretação, da Jurisprudência ao Precedente. 3.ed. São Paulo: Revista dos Tribunais, 2017. p.93.

${ }^{12}$ NERY JÚNIOR, Nelson. Teoria Geral dos Recursos. 6.ed. São Paulo: Revista dos Tribunais, 2004. p. 442.

${ }^{13}$ ALVIM, Teresa Arruda; DANTAS, Bruno. Recurso Especial, Recurso Extraordinário e a Nova Função dos Tribunais Superiores. Precedentes no Direito Brasileiro. 6.ed. São Paulo: Revista dos Tribunais, 2019. p.370. No mesmo sentido, defendendo que a revaloração da prova e dos dados explicitamente admitidos na decisão recorrida não implica o reexame do material probatório, ver SCALABRIN, Felipe. COSTA, Miguel do Nascimento. CUNHA, Guilherme Antunes da. Lições de Processo Civil - Recursos. Porto Alegre: Livraria do Advogado, 2017. p. 129.
} 
não está direcionada à dicotomia que contrapõe questões de fato a questões de Direito, mas sim à divisão de funções entre Cortes de Justiça, às quais caberia a construção de decisão para o caso concreto, e Cortes de Precedentes, às quais tocaria a formatação da interpretação do Direito a partir do caso concreto $^{14}$. Na visão do referido autor, o Superior Tribunal de Justiça deve ser pensado como Corte Suprema, sendo visto não como corte de controle e sim como corte de interpretação, como corte de precedentes ${ }^{15}$ - o que, por certo, importa não só em uma releitura substancial das hipóteses de cabimento descritas nas alíneas do art. 105, III da Constituição Federal, mas em uma releitura quanto à própria divisão de tarefas entre os órgãos do Poder Judiciário.

Nesse cenário é mais do que pertinente, ainda, a lembrança da lição de Danilo Knijnik ao propor que se admita a existência de uma distinção entre questões de fato, que se colocam à margem do controle revisional na via do recurso especial, contrapostas não só as questões de Direito, que se reconhece como sindicáveis no exame por essa via, mas também às chamadas questões mistas, nas quais se enquadram situações que não se resolvem nas categorias anteriores, "seja porque o processo interpretativo o inviabiliza, seja porque a legislação moderna torna-o inviável, seja porque o trabalho do juiz não se amolda a essa bipartição", as quais, segundo o citado autor, presentes certos requisitos, poderiam ser objeto de uma revisão in iure ${ }^{16}$.

De tudo o quanto acima exposto, é possível uma leitura crítica do âmbito de competência jurisdicional do Superior Tribunal de Justiça com vistas ao julgamento de recursos especiais de modo a apontar distinções que revelam que a negativa de seguimento fundamentada na aplicação da Súmula n ${ }^{\circ} 7$ supracitada não necessariamente é um sintoma de desrespeito ao direito fundamental à tutela jurisdicional efetiva. Ao contrário, o que se vê é que a negativa de seguimento a recursos especiais em tais casos é, antes, expressão de limites constitucionalmente desenhados à atuação do próprio Superior Tribunal de Justiça, que deve ser visto como um tribunal ao qual é atribuída competência para o exercício da jurisdição em termos bastante específicos.

14 MITIDIERO, Daniel. Cortes Superiores e Cortes Supremas: Do Controle à Interpretação, da Jurisprudência ao Precedente. 3.ed. São Paulo: Revista dos Tribunais, 2017. p.105.

15 MITIDIERO, Daniel. Cortes Superiores e Cortes Supremas: Do Controle à Interpretação, da Jurisprudência ao Precedente. 3.ed. São Paulo: Revista dos Tribunais, 2017. p.93.

${ }^{16}$ KNIJNIK, Danilo. O recurso especial e a revisão da questão de fato pelo Superior Tribunal de Justiça. Rio de Janeiro: Forense, 2005. p. 159-160. 


\section{DIREITO FUNDAMENTAL À TUTELA JURISDICIONAL EFETIVA E OS LIMITES À ATUAÇÃO DA ATIVIDADE NOTARIAL NO CONTEXTO DA DESJUDICIALIZAÇÃO E DA EXTRAJUDICIALIZAÇÃO DO ACESSO À JUSTIÇA}

Uma ulterior reflexão a ser feita diz respeito à existência de importantes pontos de contato entre a leitura crítica das normas que delimitam o âmbito de competência da atividade notarial, braço fundamental integrante do feixe de instituições projetadas com vistas à oferta de acesso à justiça, e a densificação do direito fundamental à tutela jurisdicional efetiva.

Nesse sentido, uma primeira premissa a ser considerada diz respeito ao que se entende por acesso à justiça, que aqui atua como vetor de unidade a agregar a atividade notarial em convergência com outras atividades prestacionais. Uma primeira leitura pode ser vista no pensamento de Thiago Rebellato Zorzeto ${ }^{17}$, para quem o direito ao acesso à justiça deve ser visto como direito fundamental estruturante do Estado Democrático de Direito, sendo a fundamentalidade desse direito corolário lógico da premissa de que o mesmo é um dos principais instrumentos garantidores da concretização de todos os demais direitos fundamentais.

Uma outra leitura a respeito do tema pode ser vista na lição de Ricardo Goretti ${ }^{18}$ ao referir que o direito ao acesso à justiça pode ser extraído na medida em que se considere a justiça como designação de um valor, virtude, fundamento ético de equidade e igualdade a ser perseguido judicial e extrajudicialmente, pouco importando a via utilizada para realizar direitos e interesses violados ou ameaçados de lesão. Sob essa perspectiva, o direito em questão é compreendido como a expressão do acesso à justiça pautado por uma expressão substancial ou material.

Nesse viés, o acesso à justiça pode ser compreendido na plenitude de sua dimensão social, jurídica e política, como designação do direito ao acesso à informação e à orientação jurídica e a todos os meios alternativos de composição de conflitos, sendo o acesso à ordem

\footnotetext{
${ }^{17}$ ZORZETO, Thiago Rebellato. O direito de acesso à justiça relativizado pelo interesse de agir e os meios extrajudiciais de solução de conflitos. In: (Org.) GUILHERME, Luiz Fernando do Vale de Almeida. Soluções extrajudiciais de controvérsias empresariais. v.2. Belo Horizonte: Letramento: Casa do Direito, 2016, p.11; 1617.

${ }^{18}$ GORETTI, Ricardo. Mediação e acesso à justiça. Salvador: JusPodivm, 2016, p.67-68.
} 
jurídica justa, antes de tudo, uma questão de cidadania. Portanto, revela-se alinhado com um ideal democrático de reivindicação de direitos por vias plurais de prevenção e/ou resolução de conflitos e, ainda, compreende a possibilidade de obtenção de resultados justos mediante o emprego de diferentes vias concebidas com vistas a tais desideratos. Trata-se, aqui, de uma mudança paradigmática em direção a um conceito mais abrangente de acesso à justiça ${ }^{19}$, a qual pode ser descrita ser uma tendência de dimensões mundiais, conforme se depreende, exemplificativamente, do quanto consta da Diretiva 2008/52/CE, do Parlamento Europeu e do Conselho da União Europeia, de 21 de maio de 2008.

Em um tal contexto, destaque especial deve ser dado ao movimento de extrajudicialização do acesso à justiça, que compreende a alteração do regime de competência jurisdicional de modo a fazer com que tarefas que até então eram desempenhadas de maneira exclusiva no âmbito jurisdicional possam ser praticadas por outros atores que não integrem a estrutura do Poder Judiciário. Trata-se de movimento que se situa em uma zona de sombra na qual se cruza com o da desjudicialização do acesso à justiça, que compreende também o emprego de outras atividades de solução de conflitos e/ou de reconhecimento de direitos para além da prolação de decisões pelos órgãos do Poder Judiciário, como a mediação e a conciliação.

Se, de um lado, é correto afirmar a desjudicialização do acesso à justiça tem sido vista como uma fórmula envolta em ares de novidade, especialmente em se considerando os recentes movimentos de reforma legislativa (como, por exemplo, o Projeto de Lei do Senado $n^{\circ}$ 6.204/2019, tratando do fenômeno no âmbito da atividade executiva), a atividade em sede de extrajudicialização já vinha sendo vista no ordenamento brasileiro há mais tempo, e vem retomando sua força principalmente por a ela ser associado um caráter preventivo em relação à solução de $\operatorname{conflitos}^{20}$.

Em um tal cenário, destaque especial deve ser dado, aqui, ao papel desempenhado em tal contexto pelos serviços delegados aos notários e aos registradores, os quais passam a deter competência para a prática de atos antes praticados por juízes, em uma dinâmica na qual estes, por sua vez, permanecem competentes para o julgamento de pleitos envolvendo

\footnotetext{
${ }^{19}$ SILVEIRA, Thiago Cortes Rezende. A conciliação e a mediação no registro civil de pessoas naturais sob o foco do novo código de processo civil. In: (Coords.) FERRO JUNIOR, Izaías Gomes; (Coord. geral) EL DEBS, Martha. O registro civil das pessoas naturais - novos estudos. Salvador: Juspodivm, 2017, p.489-506.

${ }^{20}$ FERNANDES, Alfredo Luís Papassoni. Extrajudicialização: a jurisdição voluntária nos serviços notariais e registrais. Bauru, SP: Spessotto, 2017, p. 33-40.
} 
a fiscalização quanto à regularidade desses mesmos $\operatorname{atos}^{21}$. É o que se vê, exemplificativamente, nos casso em que o ordenamento jurídico dispõe sobre a possibilidade de reconhecimento extrajudicial de usucapião contemplada no art. 216-A da Lei 6.015/1973, introduzido pelo art. 1.071 do Código de Processo Civil, bem como de utilização de escritura pública para fins de realização de inventário e a partilha de bens (art. 610, $\S 1^{\text {o }}$ do Código de Processo Civil) e de separação e divórcio consensuais, ou, ainda, de extinção consensual de união estável (art. 733 do Código de Processo Civil) em âmbito extrajudicial ${ }^{22}$.

A peculiar realidade do regime jurídico aplicável aos serviços notariais e registrais, ancorado no art. 236 da Constituição Federal, contemplando o binômio função estatal exercício em caráter privado, com a atribuição da atividade delegada pelo Poder Judiciário. Pense-se, nesse sentido, que a extrajudicialização de atividades faz com que procedimentos conduzidos por notários ou tabeliães não só possam estar sujeitos a intervenções decorrentes de decisões proferidas por magistrados, mas também possam, em certos casos, ser até mesmo convertidos em processos conduzidos por órgãos do Poder Judiciário, tudo isso sem solução de continuidade entre as instâncias extrajudicial e judicial.

A atribuição de competência a notários e registradores com vistas à prática de atos até então praticados exclusivamente por magistrados traz, ainda, desafios importantes do ponto de vista prático, os quais são decorrentes da natureza jurídica sui generis dos serviços notariais e registrais, nos quais se vê um amálgama a unir uma parcela de atividade que até então era exercida de maneira exclusiva por juízes a todo um outro conjunto de atividades administrativas próprias de serviços públicos. Nesse sentido, impõe-se sublinhar que o exercício de competência atribuída aos titulares de cartório pressupõe o respeito a certas limitações que não eram imponíveis aos magistrados na prática de atos destinados ao enfrentamento de realidades análogas. Nesse sentido, sob o signo da obrigatoriedade de sujeição aos princípios da Administração Pública, consagrados no art. 37 da Constituição Federal, impõe-se aos notários e registradores o dever de respeito à legalidade sem que,

\footnotetext{
${ }^{21}$ BALTAZAR, Alan Jece. Mediação e Conciliação nos Cartórios Extrajudiciais - Papel do oficial de registro de imóveis no âmbito da execução extrajudicial de bens imóveis alienados fiduciariamente. Belo Horizonte: Editora Dialética, 2021, p. 75-77.

${ }^{22}$ Os exemplos são catalogados em REICHELT, Luis Alberto. Reflexões sobre o conteúdo do direito fundamental ao acesso à justiça no âmbito cível em perspectiva contemporânea. Revista de Processo, vol. 296/2019, p. 21 - 40, Out/2019.
} 
contudo, lhes seja permitido efetuar o controle de constitucionalidade de leis ou, ainda, o recurso à equidade, providências que, diferentemente, podem ser adotadas magistrado ${ }^{23}$.

Outro limite a ser considerado no contexto da extrajudicialização do acesso à justiça mediante atribuição de competência para a prática de atos a notários e registradores é aquele constante do art. 610 do Código de Processo Civil, o qual, na trilha disposto inicialmente no art. 982 do Código de Processo Civil de 1973, com a redação dada pela Lei n. ${ }^{\circ}$ 11.441/2007, possibilita a realização de inventário e partilha através de escritura pública, desde que não haja testamento ou interessado incapaz e se todas as partes interessadas forem capazes e concordes e estiverem assistidas por advogado ou por defensor público. A esse respeito, anote-se que não obstante a disposição legal de tal limitação, salienta-se que a Consolidação Normativa Notarial e Registral do Estado do Rio Grande do Sul - CNNR, no parágrafo $2^{\circ}$ do seu art. 899, seguindo a tendência do que já ocorria em São Paulo ${ }^{24}$ permite que, havendo expressa autorização do juízo sucessório competente nos autos do procedimento de abertura e cumprimento de testamento, sendo todos os interessados capazes e concordes, poderão também ser feitos o inventário e a partilha por escritura pública.

Do mesmo modo, o Código de Processo Civil também permite, no seu art. 733 (que, por sua vez, também dá continuidade ao anteriormente previsto o art. 1.124-A do Código de Processo Civil de 1973, com a redação incluída pela Lei n. $\left.{ }^{\circ} 11.441 / 2007\right)$, que o divórcio consensual, a separação consensual e a extinção consensual de união estável, não havendo

\footnotetext{
${ }^{23}$ Acerca da aplicação deste princípio da legalidade na atividade notarial e registral, importante destacar a lição de Marcelo Guimarães Rodrigues, para quem "a natureza da Administração Pública, em que se insere a atividade desempenhada pelos tabeliães e oficiais registradores, corresponde a um múnus público para quem a exerce, equivale a um encargo de defesa, conservação e aprimoramento dos bens, serviços e interesses da coletividade. O titular da delegação deve cumprir estritamente os princípios da moral e das leis administrativas que regem a sua atividade, uma vez que ao ser investido de tal poder assume junto à coletividade o dever de bem servi-la, pois outro não é o legítimo anseio do povo como principal destinatário dos bens, serviços e interesses administrados pelo Estado. Os fins da Administração Pública se resumem a um único objetivo, o bem comum da coletividade administrada. A vontade do administrador é subjugada pelo fim, objetivo maior que domina todas as formas de administração" (RODRIGUES, Marcelo Guimarães. Tratado de registros públicos e direito notarial. 2.ed. São Paulo: Atlas, 2016, p. 168).

${ }^{24}$ Veja-se, no ponto, o constante do item 130 do Cap. XVI das Normas de Serviço dos Cartórios Extrajudiciais do Estado de São Paulo: “130. Diante da expressa autorização do juízo sucessório competente, nos autos do procedimento de abertura e cumprimento de testamento, sendo todos os interessados capazes e concordes, poderão ser feitos o inventário e a partilha por escritura pública, que constituirá título hábil para o registro imobiliário. 130.1. Poderão ser feitos o inventário e a partilha por escritura pública, também, nos casos de testamento revogado ou caduco, ou quando houver decisão judicial, com trânsito em julgado, declarando a invalidade do testamento, observadas a capacidade e a concordância dos herdeiros. 130.2. Nas hipóteses do subitem 130.1, o Tabelião de Notas solicitará, previamente, a certidão do testamento e, constatada a existência de disposição reconhecendo filho ou qualquer outra declaração irrevogável, a lavratura de escritura pública de inventário e partilha ficará vedada, e o inventário far-se-á judicialmente".
} 
nascituro ou filhos incapazes e observados os requisitos legais, poderão ser realizados por escritura pública, desde que os interessados estejam assistidos por advogado ou por defensor público. Esses limites, da mesma forma, também foram objeto de releitura no âmbito da Consolidação Normativa Notarial e Registral do Estado do Rio Grande do Sul - CNNR, no parágrafo $3^{\circ}$ do seu art. 886, que, seguindo, da mesma forma, a tendência do que já havia sido estabelecido na realidade paulista ${ }^{25}$, possibilita a lavratura de escritura pública de conversão da separação judicial em divórcio consensual mesmo que existam filhos crianças ou adolescentes ou incapazes do casal, desde que não haja nenhuma alteração do que foi convencionado e homologado na separação judicial em relação aos direitos destes filhos menores de idade ou incapazes.

Uma terceira realidade a ser considerada é a que envolve a possibilidade de usucapião extrajudicial perante o Registro de Imóveis, decorrente da introdução, pelo art. 1071 do Código de Processo Civil, do art. 216-A na Lei n. ${ }^{\circ}$ 6.015/1973. Pensado como uma fórmula destinada à formalização de situações já consolidadas, o referido comando está sujeito ao disposto no Provimento CNJ n. ${ }^{\circ} 65$ do, de 15/12/2017, editado em razão da necessidade de uniformização de procedimentos em todo o território nacional. O ponto é relevante na medida em que permite chamar a atenção, mais uma vez, para a circunstância de que um mecanismo que se coloca como uma alternativa ao emprego da via judicial acaba por se sujeitar a regimes jurídicos distintos, com diferentes condicionamentos a serem considerados com vistas à oferta de acesso à justiça, a exemplo do que se viu nos casos anteriores.

Uma ulterior situação de extrajudicialidade a ser considerada como alternativa em sede de acesso à justiça é a que envolve a realização de retificações administrativas, nos termos do previsto no art. 110 da Lei n. ${ }^{\circ}$ 6.015/1973, com a redação dada pela Lei n. ${ }^{\circ}$ 13.484/2017, e no art. 213, inciso I, da Lei n. 6.015/1973, com a redação dada pela Lei n. ${ }^{\circ}$ 10.931/2004. O primeiro comando referido permite ao registrador civil das pessoas naturais a retificação administrativa do registro, da averbação ou da anotação, de ofício ou a requerimento do interessado, mediante petição assinada pelo interessado, representante legal ou procurador, independentemente de prévia autorização judicial ou manifestação do

\footnotetext{
${ }^{25}$ Assim consta do item 87.2 do Cap. XVI das Normas de Serviço dos Cartórios Extrajudiciais do Estado de São Paulo: "87.2. Se comprovada a resolução prévia e judicial de todas as questões referentes aos filhos menores (guarda, visitas e alimentos), o tabelião de notas poderá lavrar escrituras públicas de separação e divórcio consensuais".
} 
Ministério Público, nos casos de (a) erros que não exijam qualquer indagação para a constatação imediata de necessidade de sua correção, (b) erro na transposição dos elementos constantes em ordens e mandados judiciais, termos ou requerimentos, bem como outros títulos a serem registrados, averbados ou anotados, e o documento utilizado para a referida averbação e/ou retificação ficará arquivado no registro no cartório, (c) inexatidão da ordem cronológica e sucessiva referente à numeração do livro, da folha, da página, do termo, bem como da data do registro, e (d) ausência de indicação do Município relativo ao nascimento ou naturalidade do registrado, nas hipóteses em que existir descrição precisa do endereço do local do nascimento. O segundo, por sua vez, permite ao registrador de imóveis a retificação administrativa do registro ou da averbação de ofício ou a requerimento do interessado nos casos de (a) omissão ou erro cometido na transposição de qualquer elemento do título, (b) indicação ou atualização de confrontação, (c) alteração de denominação de logradouro público, comprovada por documento oficial, (d) retificação que vise a indicação de rumos, ângulos de deflexão ou inserção de coordenadas georreferenciadas, em que não haja alteração das medidas perimetrais, (e) alteração ou inserção que resulte de mero cálculo matemático feito a partir das medidas perimetrais constantes do registro, (f) reprodução de descrição de linha divisória de imóvel confrontante que já tenha sido objeto de retificação, e (g) inserção ou modificação dos dados de qualificação pessoal das partes, comprovada por documentos oficiais, ou mediante despacho judicial quando houver necessidade de produção de outras provas. Também em tais hipóteses as peculiaridades no que se refere ao respeito à legalidade estrita, à impossibilidade de controle de constitucionalidade de leis e à sujeição a regimes jurídicos distintos em relação àqueles aplicáveis na submissão de tais questões à apreciação judicial revelam a existência de um debate legítimo a ser travado a respeito não só dos limites a serem observados pelo tabelião e pelo registrador, mas também da qualidade das normas a serem respeitadas com vistas à oferta de tutela jurisdicional efetiva àqueles que buscam providências análogas mediante o recurso ao Poder Judiciário.

\section{CONCLUSÃO}

Ao final do presente trabalho, constata-se que as regras de competência associadas a atividades exercidas por órgãos do Poder Judiciário e por outros agentes que com ele 
cooperam acabam por exercer determinante influência na forma como se manifesta o respeito ao direito fundamental à tutela jurisdicional efetiva em favor do cidadão.

Verificou-se, a partir da consideração de abordagens distintas, diversas formas de equalização entre o direito fundamental em questão e o direito fundamental à segurança jurídica. O exame do filtro de admissibilidade de relevância de recursos especiais traz consigo a transformação da função exercida pelo Superior Tribunal de Justiça, reclamando atenção para desafios ulteriores, para além dos moldes projetados pelo texto constitucional - e, com isso, abrindo as portas para o legítimo questionamento a respeito da existência de ganhos ou de prejuízos a serem verificados no que se refere à oferta de tutela jurisdicional efetiva. A análise dos limites impostos pela Súmula $\mathrm{n}^{\circ} 7$ do mesmo tribunal, por sua vez, revelam, da mesma forma, um desenho institucional no qual aquela corte exerce um papel diferenciado no quadro de organização judiciária, no que vem encartada a necessidade de leitura crítica sobre os papéis exercidos pelos diferentes órgãos jurisdicionais com vistas a garantir ao jurisdicionado proteção capaz de atender ao estabelecido no ordenamento jurídico pátrio. Por fim, as reflexões sobre a competência de notários e registradores para a prática de atos em sede de desjudicialização e de extrajudicialização de medidas em sede de acesso à justiça revelou, por sua vez, a existência de diferentes requisitos a serem considerados com vistas à prática de atos análogos perante órgãos jurisdicionais, de modo a legitimar o questionamento sobre se as providências adotadas em juízo seriam hábeis a viabilizar proteção mais efetiva ao cidadão do que aquelas adotadas por outros agentes.

Tem-se, pois, ao final do presente estudo, mais do que um conjunto de análises exaurientes de problemas práticos, uma sinalização no sentido de que a consideração das regras de competência associadas aos diferentes agentes envolvidos no sistema de acesso à justiça impõe sempre a indagação crítica sobre a necessidade de respeito ao direito fundamental à tutela jurisdicional efetiva, que serve como um indicativo seguro a ser considerado para que se possa mensurar a qualidade dos meios dispostos pelo ordenamento jurídico com vistas à tutela de direitos.

\section{REFERÊNCIAS:}


ALVIM, Teresa Arruda; DANTAS, Bruno. Recurso Especial, Recurso Extraordinário e a Nova Função dos Tribunais Superiores. Precedentes no Direito Brasileiro. 6.ed. São Paulo: Revista dos Tribunais, 2019.

ÁVILA, Humberto. Teoria da Segurança Jurídica. $6^{\text {a }}$ edição. Salvador: Juspodivm, 2021.

BALTAZAR, Alan Jece. Mediação e Conciliação nos Cartórios Extrajudiciais - Papel do oficial de registro de imóveis no âmbito da execução extrajudicial de bens imóveis alienados fiduciariamente. Belo Horizonte: Editora Dialética, 2021.

BRASIL. Senado Federal. Proposta de Emenda à Constituição nº 10, de 2017. Acrescenta $\S$ $1^{\circ}$ ao art. 105 da Constituição Federal e renumera o atual parágrafo único. Disponível em https://www25.senado.leg.br/web/atividade/materias/-/materia/128403. Acesso em 19.11.2021.

BRASIL. SUPERIOR TRIBUNAL DE JUSTIÇA. Assessoria de Modernização e Gestão Estratégica. Coordenadoria de Gestão da Informação. Relatório Estatístico 2020. Disponível em https://www.stj.jus.br/webstj/Processo/Boletim/verpagina.asp?vPag=0\&vSeq=357. Acesso em 18.11.2021.

CABRAL, Antonio do Passo. Juiz, Natural e Eficiência Processual. São Paulo: Revista dos Tribunais, 2021.

CÔRTES, Osmar Mendes Paixão. Recurso extraordinário: da Constituição Federal de 1988 ao atual CPC. Revista de Processo, vol. 289, p.21-45, mar. 2019.

FERNANDES, Alfredo Luís Papassoni. Extrajudicialização: a jurisdição voluntária nos serviços notariais e registrais. Bauru, SP: Spessotto, 2017.

GOMES JUNIOR, Izaías; (Coord. geral) EL DEBS, Martha. O registro civil das pessoas naturais - novos estudos. Salvador: Juspodivm, 2017.

GORETTI, Ricardo. Mediação e acesso à justiça. Salvador: JusPodivm, 2016.

JOBIM, Marco Félix. As Funções da Eficiência no Processo Civil Brasileiro. São Paulo: Revista dos Tribunais, 2017.NERY JÚNIOR, Nelson. Teoria Geral dos Recursos. 6.ed. São Paulo: Revista dos Tribunais, 2004.

KNIJNIK, Danilo. O recurso especial e a revisão da questão de fato pelo Superior Tribunal de Justiça. Rio de Janeiro: Forense, 2005. 
MEDINA, José Miguel Garcia. Prequestionamento, repercussão geral da questão constitucional, relevância da questão federal: admissibilidade, processamento e julgamento dos recursos extraordinário e especial. 7. ed. São Paulo: Rev. dos Tribunais, 2017.

OLIVEIRA, Pedro Miranda de. Para uma efetividade maior do instituto da repercussão geral das questões constitucionais. Revista Dialética de Direito Processual vol.145, p. 60-81, abr. 2015.

PINTO, José Guilherme Berman Corrêa. Repercussão geral no recurso extraordinário. 2. ed. Curitiba: Juruá, 2016.

REICHELT, Luis Alberto. Reflexões sobre o conteúdo do direito fundamental ao acesso à justiça no âmbito cível em perspectiva contemporânea. Revista de Processo, vol. 296/2019, p. $21-40$, Out/2019.

RIBEIRO, Flávia Pereira. Conceito e análise da repercussão geral. Revista Síntese de Direito Civil e Processual Civil, vol. 110, p. 84-86, nov./dez. 2017.

RODRIGUES, Marcelo Guimarães. Tratado de registros públicos e direito notarial. 2.ed. São Paulo: Atlas, 2016.

SCALABRIN, Felipe. COSTA, Miguel do Nascimento. CUNHA, Guilherme Antunes da. Lições de Processo Civil - Recursos. Porto Alegre: Livraria do Advogado, 2017.

SILVA, Carlos Augusto. O princípio do juiz natural. Revista da Ajuris, vol. 30, p. 9-28, mar. 2003.

SILVA, Christine Oliveira Peter da. Repercussão geral em evolução: narrativa histórica, teórica e metodológica. Revista Síntese de Direito Civil e Processual Civil, vol. 110, p. 9-32, nov./dez. 2017.

SILVEIRA, José Néri da. Reflexos da exigência de 'repercussão geral das questões constitucionais discutidas no caso' sobre a natureza e a amplitude do recurso extraordinário. Revista do Tribunal Regional Federal da Quarta Região, vol. 88, p. 15-44, 2015.

SILVEIRA, Thiago Cortes Rezende. A conciliação e a mediação no registro civil de pessoas naturais sob o foco do novo código de processo civil. In: (Coords.) FERRO 
Revista Eletrônica de Direito Processual - REDP.

Rio de Janeiro. Ano 16. Volume 23. Número 1. Janeiro a Abril de 2022

Periódico Quadrimestral da Pós-Graduação Stricto Sensu em Direito Processual da UERJ

Patrono: José Carlos Barbosa Moreira (in mem.). ISSN 1982-7636. pp. 852-871 www.redp.uerj.br

SOUZA, Artur César de. Recurso extraordinário e recurso especial: pressupostos e requisitos de admissibilidade no novo CPC: de acordo com a Lei 13.256, de 4/2/2016. São Paulo: Almedina, 2017.

ZORZETO, Thiago Rebellato. O direito de acesso à justiça relativizado pelo interesse de agir e os meios extrajudiciais de solução de conflitos. In: (Org.) GUILHERME, Luiz Fernando do Vale de Almeida. Soluções extrajudiciais de controvérsias empresariais. v.2. Belo Horizonte: Letramento: Casa do Direito, 2016. 